\title{
Fragile Heterosexuality
}

\author{
Keon West ${ }^{1}$, Martha Lucia Borras-Guevara ${ }^{1}$, Thomas Morton², and Katy Greenland ${ }^{3}$ \\ ${ }^{1}$ Equalab, Department of Psychology, Goldsmiths, University of London, United Kingdom \\ ${ }^{2}$ Department of Psychology, University of Copenhagen, Denmark \\ ${ }^{3}$ School of Social Sciences, Cardiff University, United Kingdom
}

\begin{abstract}
Previous research demonstrates that membership of majority groups is often perceived as more fragile than membership of minority groups. Four studies $\left(N_{1}=90, N_{2}=247, N_{3}=500, N_{4}=1,176\right)$ investigated whether this was the case for heterosexual identity, relative to gay identity. Support for fragile heterosexuality was found using various methods: sexual orientation perceptions of a target who engaged in incongruent behavior, free-responses concerning behaviors required to change someone's mind about a target's sexual orientation, agreement with statements about men/women's sexual orientation, and agreement with gender-neutral statements about sexual orientation. Neither participant nor target gender eliminated or reversed this effect. Additionally, we investigated multiple explanations (moderators) of the perceived difference in fragility between heterosexual identity and gay identity and found that higher estimates of the gay/lesbian population decreased the difference between the (higher) perceived fragility of heterosexual identity and the (lower) perceived fragility of gay identity.
\end{abstract}

Keywords: fragile sexual orientation, heterosexuality, gay, estimates of gay/lesbian population, social normativity

Asymmetrical perceptions of sexual orientation matter because people who are identified as belonging to a sexual minority group (e.g., gay people) are subjected to discrimination, violence, and stereotyping (Mishel, 2016; Powell et al., 2015). Diverse types of evidence (mostly qualitative) allude to the idea that heterosexual identity is perceived as more fragile (i.e., easily compromised) than gay identity (Anderson, 2005; Lee, 2006; Mize \& Manago, 2018). This fragility refers to the relative ease with which one's heterosexual status can be lost, compared to that of gay status. The aim of this research is to investigate the proposed asymmetry in perceptions of the fragility of heterosexual identity versus gay identity and to explore potential psychological explanations for this phenomenon.

Anderson (2008) introduced the "one-drop rule" of sexual orientation (Anderson, 2005, p. 45) to describe the relative fragility of heterosexuality and the relative robustness of being gay. This "one-drop rule" is similar to the one-drop rule of Black racial identification (Khanna, 2010), and claims that one same-sex experience is enough to categorize someone as gay, whereas one opposite-sex experience is not sufficient to consider someone heterosexual. Anderson (2005) likely intended this one-drop rule to be illustrative, rather than absolute. Indeed, Anderson et al. (2012) showed that same-sex behaviors in men can be construed as bonding between members of a sports team, rather than signs of being gay. Nonetheless, other anecdotal evidence strongly indicates the relative fragility of heterosexual identity versus gay identity. On October 3, 2003, in Newark, California, USA, Michael Magidson and Jose Merel beat Gwen Araujo to death after having sex with her, when they discovered she was transgender (Lee, 2006). At their trial, Michael and Jose argued that their discovery had felt like a "theft of [their] heterosexuality" (C. Lee \& Kwan, 2014, p. 111) and that Gwen's deception had made them gay, an outcome so distressing that it led to murderous panic. To Michael and Jose, the few, recent sexual encounters with Gwen were enough to threaten their heterosexuality, making them feel gay, whereas their extensive sexual history with cisgender women was not sufficient to assure their heterosexuality (Lee \& Kwan, 2014, p. 111).

Few studies have done quantitative research on the fragility of heterosexuality, and these have produced inconsistent results (Duran et al., 2007; Flanders \& Hatfield, 2014; Mize \& Manago, 2018). Duran and colleagues (2007) found initial evidence of the fragility of heterosexuality. In their studies, lower number of behaviors was required to change participants' views about another person's heterosexual identity than another person's gay identity. Similarly, Flanders and Hatfield (2014) found that participants assigned sexual minority status (i.e., "bisexual") to a target who displayed minor evidence of same-sex attraction in the context of more considerable evidence of heterosexual dating: a categorization that was particularly rigid for male versus female targets (Flanders \& Hatfield, 2014). Mize and Manago (2018) found a similar fragile heterosexuality effect, that applied only to men and not women; suggesting that women were allowed more sexual freedom to have same-sex experiences without compromising perceptions of their heterosexuality.

Together these studies strongly suggest that there are different standards for classifying individuals as heterosexual 
versus gay. However, beyond this overarching similarity, these studies do have certain limitations. These include restricted, student sampling and a lack of replication (Duran et al., 2007; Flanders \& Hatfield, 2014), as well as limitations that more seriously curtail interpretation and generalisability. For example, Flanders and Hatfield (2014) found that it was easy to change perceptions of heterosexuality, but did not compare this with the ease of changing perceptions of any other sexual orientation (e.g., gay). Thus, it is unclear from their studies whether heterosexuality is particularly fragile compared to other sexual orientations. Duran et al. (2007) found that fewer behaviors were required to change perceptions of heterosexual identity than perceptions of gay identity, but made no attempt to investigate the type of behaviors. It is thus possible that participants were simply thinking of different behaviors. Additionally, Duran et al. (2007) did not specifically investigate whether the fragility of heterosexuality applied to women as well as men.

Mize and Manago (2018) conducted studies with large numbers of participants $(N=1,965)$ and replicated findings. However, their findings diverge from those of the prior research in that they found that the fragile heterosexuality effect did not apply to women. This is possibly due to their design and analysis strategy which focused on the difference between men and women, rather than the differences between heterosexuality and other sexual orientations. Furthermore, though they hypothesized some plausible explanations for the fragile heterosexuality effect (and why it did not occur in women) none of the explanations were tested empirically.

This current research builds on the afore-mentioned evidence for the asymmetry in fragility perceptions between heterosexual and gay identities. We investigated the asymmetry in a new social context (Britain); we tested the effect using a variety of methodologies; we specifically and explicitly investigated whether the effect applied to women as well as men (as well as possible differences in the strength of the effect across genders); and we explored a number of potential psychological explanations for the effect. Due to the lack of consensus regarding the effect of gender, we remain somewhat agnostic about its effects. However, we do not expect gender to eliminate the fragile heterosexuality effect, but perhaps merely to attenuate its strength.

Asymmetrical perceptions of other social constructs of majority and minority groups have been explained by processes related to social normativity (Monteith et al., 1996; Costa-Lopes et al., 2012; Dovidio et al., 1995). This approach, suggests that asymmetric perceptions of social groups reflect a society's transformation of standards, which are constituted by what is most common or accepted behavior (Zarate \& Smith, 1990).
The normativity model is based on people's tendency to adjust their behavior and opinions in line with social norms (Miller \& Prentice, 1996). This model has been used to explain regional differences in the racial categorization of biracial stimuli (Chen et al., 2018). For instance, in certain parts of the USA, Black populations are denser and more visible than any other. In these localized contexts, Whites might stand out more, grab perceptual attention, and be perceived as deviant (not the norm or default) relative to the Black norm (majority group). In fact, Chen and colleagues (2018) argue that differences in the racial categorization of biracial stimuli between Americans and Brazilians reflect the historical dissimilarities in the majority/minority racial makeup of these two countries, where the racial majority group status boundaries were opposite.

Norm perception is therefore a dynamic process where people learn about social norms over time, constantly revising their impressions according to the interactions they have within and outside their group, or through other sources of information (Monteith et al., 1996; Tankard \& Paluck, 2016; Zarate \& Smith, 1990). Within this model, descriptive norms are what Monteith and colleagues (1996) refer to as summary information about a reference group. This type of information refers to data about a group that provides the benchmark and contrast needed for general comparison between groups (Monteith et al., 1996), creating social change by modifying people's opinions and behaviors (Tankard \& Paluck, 2016).

In the context of sexuality, it is clear that a majority of people identify as heterosexual. Population-based studies revealed that in the United Kingdom, $12 \%$ of adults (roughly 8 million), identify themselves as being part of the LGBTQ community (EuroClinix, 2018). Although, other sources report that only $2 \%$ of the population is LGBTQ (Office for National Statistics - Annual Population Survey, 2019). Hence, in Britain, the social norm (the defaultmajority group) would be being heterosexual while being gay would be the exception (minority group). However, there can be regional and individual differences in estimates of population size (descriptive norm) relative to the heterosexual majority. Given the above, individual perceptions of estimates of the gay/lesbian population seem like a suitable candidate for summary information about a group that could help understand the asymmetrical fragility perceptions of sexual orientation.

Besides the normativity model, biased perceptions of majority identities have been explained in terms of contact between groups (i.e., quantity and quality; Pettigrew et al., 2010; Wagner et al., 2003, 2006), prejudice against the minority group (i.e., prejudice against gay population; Duran et al., 2007; Martinez et al., 2008), or broader intergroup ideologies, like right-wing authoritarianism or social 
dominance orientation (i.e., Ho et al., 2013), hence their inclusion as moderators in this study.

Contact between groups is more likely to happen when the population of the minority group grows (Pettigrew et al., 2010). Individuals who report more positive contact with minority groups, show less asymmetrical perceptions between groups (Harwood et al., 2005; Paolini et al., 2004; Plant \& Devine, 2003). In terms of prejudice against the minority group, individuals with higher prejudice against gay people, show significantly more asymmetrical perceptions between being heterosexual and being gay (Duran et al., 2007). In parallel, multiple studies have found more racial asymmetric perceptions (i.e., "Black" vs. "White") for participants high in right-wing authoritarianism (those who stick to social norms, while being hostile and punishing toward people who challenge societal conventions: Dhont \& Van Hiel, 2011), as well as for individuals high on the social dominant orientation scale (those who endorse beliefs, and policy-related actions, that enhance hierarchical differentiation between groups; Ho et al., 2011; Whitley, 1999). Accordingly, it is theoretically important to understand the explanatory contribution of certain ideological attitudes and between-group interactions in the asymmetrical fragility perceptions between heterosexual identity and gay identity.

\section{The Current Research}

Besides replicating findings from the USA within a heterosexual, British population, we aimed to demonstrate that heterosexual identity is perceived as more fragile (easily compromised) than gay identity using four different methodologies, and to test possible explanations for this asymmetry.

To address these aims, we investigated fragility perceptions of sexual orientation (heterosexual identity vs. gay identity), and six possible moderators of the effect. In terms of measures of the fragility of sexual orientation, we used three different approaches. The first approach involved analyzing participants' perceptions of a male target who engaged in behavior that contradicted his disclosed sexual orientation (Study 1). The second examined participants' free-response concerning behaviors required to change someone's mind about the sexual orientation of a male target (Study 2a) or female target (Study 2b). We acknowledge, that perceptions of masculinity and heterosexuality (in men) are intertwined, sexual and gender identities are also separate constructs, and accordingly, they should not be treated as redundant (i.e., gay men can be masculine or feminine; see, Glick et al., 2007). While this research strongly connects with ideas about gender identities, it is novel in focusing on sexual identities. Moreover, by testing the fragility of heterosexuality in women as well as men, our investigation will empirically consider the fragility of heterosexuality across gender identities and thereby will answer the question of whether this is reducible to masculinity concerns.

For the third and fourth studies, participants indicated their agreement with 14 statements related to the fragility of heterosexual identity (or gay identity), for each gender (Study 3) or in a gender-neutral version (Study 4). Additionally, Study 4 investigated the underlying explanations (moderation effects) for the effects observed: participants' estimates of gay/lesbian population, social dominance orientation, right-wing authoritarianism, prejudice against gay/lesbian people, contact quantity, and contact quality.

Based on previous findings, we expected an asymmetry in fragility perceptions between heterosexual identity and gay identity, that is, heterosexual identity should be perceived as more fragile than gay identity. We predicted that the effect would occur for both men (Studies 1, 2, and 3) and women (Studies 2 and 3), though the effect may be smaller for women (Studies 2 and 3). Additionally, based on the social normativity model, we predicted that the asymmetry in fragility perceptions between heterosexual identity and gay identity would be moderated by individual estimates of the gay/lesbian population. As participants report higher estimates of the gay/lesbian population, the asymmetry between the (higher) perceived fragility of heterosexual identity and the (lower) perceived fragility of gay identity should be smaller. We hypothesize that when gay identity is more prevalent (i.e., higher estimates of gay/lesbian population), there would be a decrease in fragility perceptions of heterosexual identity and an increase for gay identity. Further, we do not have specific predictions for the other five moderators but their inclusion was needed to rule out their effects as alternative explanations for the results found here. Finally, as a methodological note, we aimed to be as consistent as possible across all the studies and to rule out possible spurious effects based on demographic variables. Thus, across all studies, if participants' age and gender were not independent variables, they were included as covariates.

\section{Study 1}

This was an initial test of heterosexual identity being perceived as more fragile (easily compromised) than gay identity. All participants received information about a target (named James) who described himself as either gay or heterosexual. Participants then read a vignette in which "James" behaved in a way that contradicted his professed sexual orientation. We predicted that participants would 
(A)

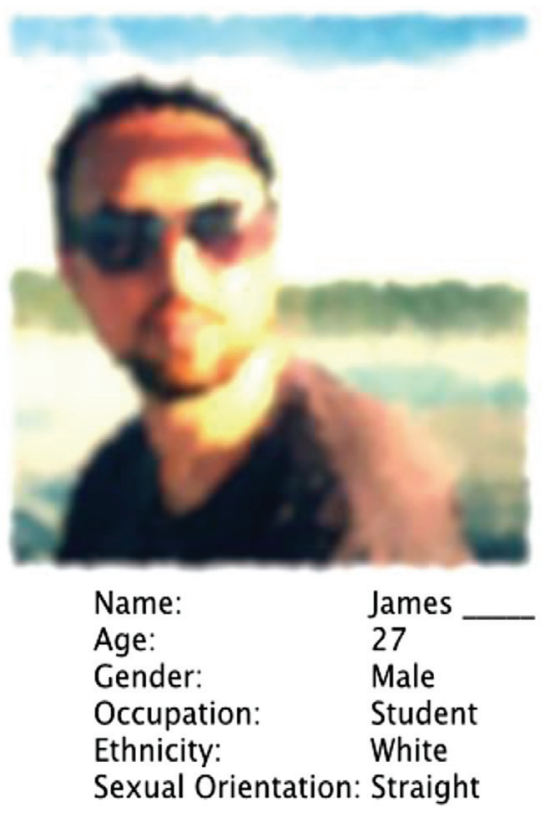

(B)

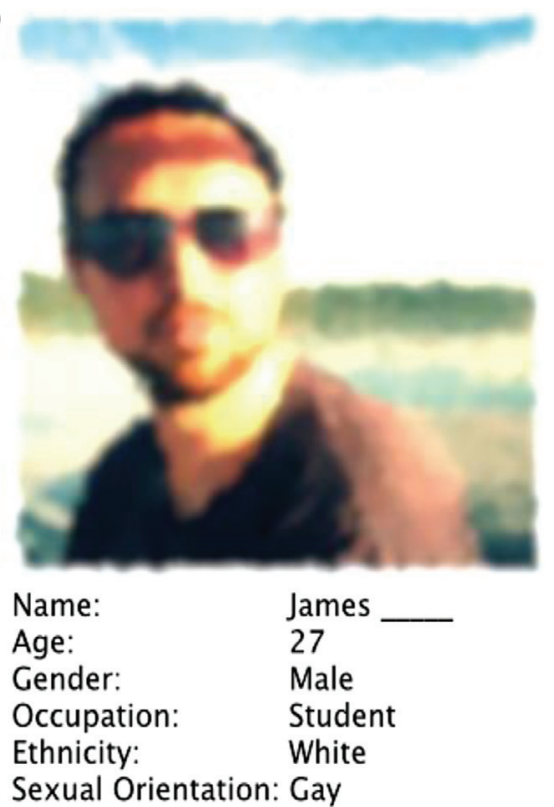

Figure 1. Stimuli used as social-media-based profiles of James in Study 1. James' straight profile (A); his gay profile (B). Participants saw only one profile, which varied by condition.

alter their perceptions of James' sexuality more strongly if he described himself as heterosexual and then engaged in a same-sex intimate act, than if he described himself as gay and then engaged in an opposite-sex intimate act.

Based on condition effects observed in a previous pilot study when assuming a similar effect size $\left(\eta^{2}=.2\right)$, and the following parameters $(\alpha=.05$; power $=0.9)$, we found that 82 participants would be required for adequate power. Assuming a 5-10\% loss of data after exclusions and reliability checks, we calculated a final sample size of 90 participants.

\section{Method}

\section{Participants and Recruitment}

Using snowball sampling and posters distributed throughout London, we recruited 90 heterosexual, White, British adults (33 men, 57 women, $M_{\text {age }}=32.85, S D=15.29$ ), who conducted our experiment using pen and paper. Participants entered a prize draw in exchange for their participation. Two participants were excluded as they did not complete the relevant questions for this study. The full dataset is available in Electronic Supplementary Material, ESM 2.

\section{Study Design}

This was a 2 (Condition: presented as heterosexual vs. presented as gay) $\times 2$ (Time: before contradicting behavior vs. after contradicting behavior) factorial design with repeated measures on the second factor.

\section{Materials and Procedure}

Participants were randomly assigned to one of two conditions. In the "heterosexual" condition, they saw a socialmedia profile description of a man (James) who described himself as heterosexual (Figure 1). We further emphasized that James was heterosexual by having him mention that he "had [his] share of girlfriends" in a self-descriptive paragraph. Participants in the "gay" condition received identical information, except that James described himself as gay, and mentioned having "had [his] share of boyfriends" in the self-descriptive paragraph. After reading this description, participants in both conditions indicated their perceptions of James using a number of traits, including his apparent sexual orientation (the critical measure) and five filler traits ("liberal," "intelligent," "cold," "trustworthy," and "friendly").

After the initial rating, participants in the "heterosexual" condition then read a vignette about James in which he went to a party and was seen kissing a man. Participants in the "gay" condition read a vignette about James kissing a woman (i.e., in both conditions James behaved in a way that contradicted his previously stated sexual orientation). After reading their respective vignettes, participants indicated once more, their perception of James for the same traits: his apparent sexual orientation and the five filler traits.

At both time points participants indicated their perceptions of James' sexual orientation using a 100-point sliding scale that was anchored by two extremes: $100 \%$ gay and $100 \%$ heterosexual. Please note that these were merely the labels used at the anchor points of the scale meant to 
Table 1. Results for the repeated measures analysis of variance done for Study 1

\begin{tabular}{lcccc}
\hline Effects & $N$ & $F$ & $p$ value & $\eta^{2}$ \\
\hline Condition & 84 & 25.19 & $<.001$ & .233 \\
Age & 84 & 0.00 & .98 & $<.001$ \\
Participant's gender & 84 & 0.01 & .91 & $<.001$ \\
Time & 84 & 43.45 & $<.001$ & .342 \\
Condition $\times$ Time & 84 & 8.43 & .005 & .091 \\
\hline
\end{tabular}

Note. Residuals of the dependent variable at both times, were normally distributed (skewness and kurtosis between \pm 0.5 ). Values in bold indicate significant effects.

indicate that participants saw the target as either entirely gay or entirely heterosexual. In terms of the dimensions, the scale was a 100-point sliding scale. The critical measure and filler items were presented in a different randomized order for each participant at each time point.

\section{Results}

For these analyses, sexual orientation scores at both time points were coded so that higher scores indicated stronger beliefs in James' professed sexual orientation. We analyzed the data with a 2 (Condition: Presented as heterosexual vs. Presented as gay) $\times 2$ (Time: Before vs. After) mixed analysis of variance with repeated measures on the second factor and belief in James' professed sexual orientation as the dependent variable. Age and participant's gender were included as covariates.

We found a main effect of condition; overall participants more strongly believed James' professed sexual orientation in the presented as gay condition $(M=78.14, S E=2.04)$ than in the presented as heterosexual condition $(M=$ $63.48, S E=2.08$ ). There was no significant effect of age or participant's gender. There was a significant effect of time; overall participants more strongly believed James' professed sexual orientation before the contradictory behavior $(M=91.1, S E=1.31)$ than after the contradictory behavior $(M=50.52, S E=2.52)$. Most importantly, we found the hypothesized interaction of condition and time. As predicted, participants' perceptions of James' sexual orientation were more strongly affected if he professed to be heterosexual, but then took part in a same-sex intimate act (a $48.73 \%$ difference; $M=87.89, S E=1.85$ vs. $M=$ $39.16, S E=3.56 ; t(44)=10.93, p<.001)$, than if he professed to be gay, but then took part in a single oppositesex intimate act (a 32.5\% difference; $M=94.37, S E=1.81$ vs. $M=61.87, S E=3.48 ; t(46)=10.07, p<.001)$; see Table 1 for detailed statistics and Figure 2 for a graphical representation.

Note also that, in the presented as heterosexual condition, participants' perceptions of James' sexual orientation dipped below the $50 \%$ point to $39.15 \%$, after his apparently

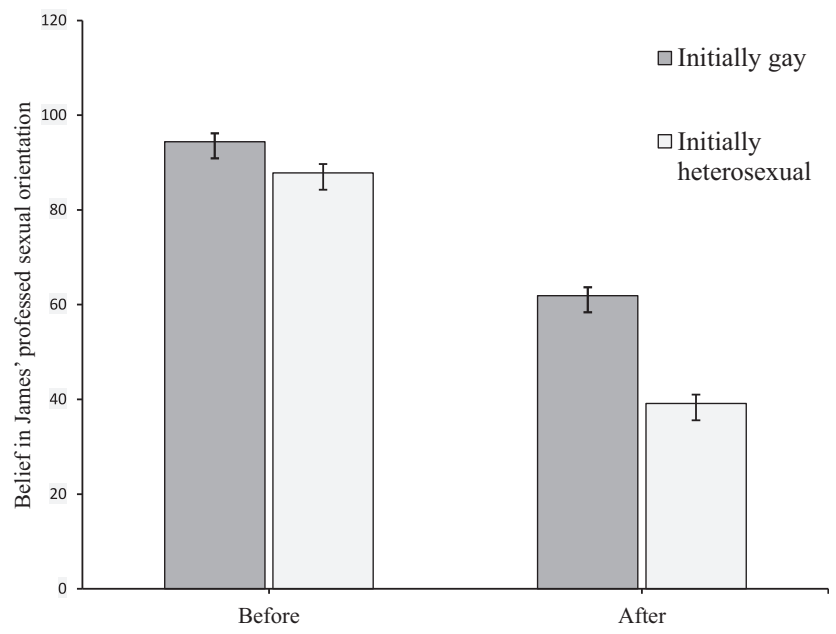

Figure 2. The effect of contradictory behavior on perceived sexual orientation according to initial presentation (Study 1). Error bars represent standard errors.

incongruent behavior. Whereas, participants' perceptions of James' sexual orientation remained above the $50 \%$ point (at $61.88 \%$ ), after his contradictory behavior.

\section{Study $2 a$ and $2 B$}

Study 1 provided evidence that heterosexual identity is perceived as more fragile than gay identity: one contradictory experience undermined the professed heterosexual identity more strongly than the professed gay identity. Study $2 \mathrm{a}$ and $2 \mathrm{~b}$ tested the fragile heterosexuality hypothesis using a different methodology: one that relied on participants' spontaneously generated ideas. In this study, participants imagined that a friend of theirs changed their mind about a male (Study 2a) or female (Study 2b) friend's sexual orientation. Participants reported what they thought happened to make their friend change their mind. In line with the fragile heterosexuality hypothesis, we expected less consequential (serious) behaviors required to compromise someone's perceived heterosexuality (vs. someone being perceived as gay).

\section{Method}

\section{Participants and Recruitment}

Recruitment was the same as in Study 1. Two hundred forty-seven participants were recruited for Study 2a (161 women, 75 men, 11 did not state their gender; $M_{\text {age }}=$ $25.42, S D=10.97)$ and 1,563 participants for Study $2 \mathrm{~b}$ (1,004 women, 477 men, 82 did not state their gender; $\left.M_{\text {age }}=24.31, S D=9.71\right)$. We predicted a smaller effect size for Study $2 b$, as women's sexuality is more dynamic than 
that of men (Diamond, 2000; Kinnish et al., 2005), therefore more participants were recruited. However, the difference in sample size does not merely reflect the difference in the expected effect size; participant recruitment was also much faster and easier for Study $2 b$, perhaps due to it being a different time of the year. Participants who did not disclose their gender were excluded, leaving a final sample size of 1,481 . Participants entered a prize draw in exchange for their participation. The full dataset is available in ESMs 3 and 4 .

\section{Study Design}

Both studies used a between-participants design. Participants were randomly assigned to one of two conditions. In the first condition, they indicated what was required to make a man (Study 2a) or woman (Study 2b) who was initially perceived as heterosexual be subsequently perceived as gay. In the second condition, they indicated the reverse: what was required to make a man/woman who was initially perceived as gay be subsequently perceived as heterosexual.

\section{Materials and Procedure}

When assigned to the "initially heterosexual condition," participants read the following instructions: "Imagine that you are having a drink with friends. In the course of conversation, one of your friends says the following: 'You guys know James (Study 2a) or Jenny (Study 2b), right? I used to think he/she was straight, but I do not think so anymore...'. Write down what you think might have happened to make your friend change his/her mind about James (or Jenny)." In the initially gay condition, the instructions were almost identical, except that the friend said, "You guys know James (or Jenny: Study 2b), right? I used to think he/ she was gay, but I do not think so anymore ...”.

After reading these instructions participants indicated what they thought might have happened to make their friend change his/her mind about James' (or Jenny's) sexual orientation. Before analyses were run, participants' responses were blinded so that it was not clear whether they referred to same-sex or opposite-sex behavior. For each study, two research assistants, blind to the hypotheses and conditions of the studies, rated each response in terms of its apparent seriousness on a 5 -point scale $(1=$ very trivial, $5=$ very serious). Examples of very trivial responses identified by the research assistants included, "visiting a bar normally frequented by people of a particular sexual orientation" and "being very friendly with someone of a particular gender." Examples of very serious responses included, "being in a serious, long-term sexual and romantic relationship with someone of a particular gender" and "explicitly coming out/declaring a particular sexual orientation." For Study 2a, the seriousness scores of the two raters were significantly correlated $(r=.77, p<.001)$, as well as for
Study $2 \mathrm{~b}(r=.88, p<.001)$. Moreover, there was a moderate agreement between raters in Study $2 \mathrm{a}(\kappa=.55 ; p<.001)$ and substantial agreement between raters in Study $2 \mathrm{~b}(\kappa=$ $0.7 ; p<.001)$. Therefore, in both studies, the mean of the two raters was used as the dependent variable. In line with fragile heterosexuality, we predicted that it would require relatively trivial behaviors for James/Jenny to no longer be perceived as heterosexual, but relatively serious behaviors for James/Jenny to no longer be perceived as gay.

\section{Results}

We ran two separate ANCOVAS - one for each study - that included the seriousness of behaviors required to compromise someone's perceived heterosexual identity (vs. gay identity) about "James" or "Jenny" as the dependent variable, condition as a fixed factor, and participant's age and gender as covariates. This analysis revealed that the seriousness of behaviors required to compromise someone's perceived heterosexual identity (vs. gay identity) about "James" or "Jenny," were not predicted by participant's age or participant's gender. In line with our prediction, the seriousness of behaviors reported by participants was significantly different depending on the condition. Participants assigned to the "initially heterosexual condition" reported less serious behaviors (James: $M=2.23, S D=$ 1.19; Jenny: $M=2.31, S D=0.91$ ) required to change someone's mind about the target being heterosexual than those assigned to the "initially gay condition" (James: $M=2.86$, $S D=1.28$; Jenny: $M=2.88, S D=1.23$ ). For detailed statistics see Table 2.

Results from Study $2 \mathrm{a}$ and Study $2 \mathrm{~b}$ suggest that regardless of the gender of the protagonist in each condition (Jenny vs. James) the seriousness of the behaviors that would change someone's mind about the protagonist being heterosexual are less serious than those associated with changing someone's mind about the protagonist being a gay.

\section{Study 3}

Studies $2 \mathrm{a}$ and $2 \mathrm{~b}$ supported our hypotheses of fragile heterosexuality. For Study 3, we sought to confirm our hypotheses using yet another methodology (measuring participants' agreements with particular statements), and develop a set of reliable items that measure fragile heterosexuality beliefs.

Based on condition effects observed in a previous pilot study, an a priori power analysis was run to test interactions between condition, target gender, and participant gender. Using the following parameters $\left(f^{2}=0.02, \alpha=.05\right.$, power $=0.9$, number of groups $=8$ ), we found that 472 
Table 2. Results for the ANCOVA done for Study $2 a$ and Study $2 b$

\begin{tabular}{|c|c|c|c|c|c|c|}
\hline \multirow[b]{2}{*}{ Effects } & \multicolumn{6}{|c|}{ James as target (Study 2a) } \\
\hline & $N$ & $F$ & $p$ value & $\eta^{2}$ & $\beta$ & $\mathrm{Cl}$ \\
\hline Age & 232 & 0.03 & .86 & $<.001$ & -0.001 & {$[-0.016,0.013]$} \\
\hline Gender & 232 & 0.08 & .77 & $<.001$ & 0.050 & {$[-0.294,0.395]$} \\
\hline \multirow[t]{2}{*}{ Condition } & 231 & 14.69 & $<.001$ & .06 & 0.623 & {$[0.303,0.943]$} \\
\hline & \multicolumn{6}{|c|}{ Jenny as target (Study 2b) } \\
\hline Age & 1,458 & 0.06 & .81 & .001 & 0.001 & {$[-0.005,0.007]$} \\
\hline Gender & 1,458 & 1.37 & .24 & .001 & -0.072 & {$[-0.191,0.048]$} \\
\hline Condition & 1,458 & 101.51 & $<.01$ & .06 & 0.574 & {$[0.465,0.683]$} \\
\hline
\end{tabular}

Note. Residuals of the seriousness of behaviors required to compromise someone's perceived heterosexuality (vs. homosexuality) were normally distributed (skewness and kurtosis between (James: \pm 0.68 ; Jenny: \pm 0.74 ). Values in bold indicate significant effects.

participants would be required for adequate power. Assuming a $5-10 \%$ loss of data after exclusions and reliability checks, we calculated a final sample size of 500 participants. For further assurance of the robustness of any findings from this study, all parameters were preregistered via AsPredicted. org (http://aspredicted.org/blind.php?x=vh25cy). Analyses reported here are those stated in the preregistration.

We based this study's methodology on that of Vandello et al. (2008, Experiment 1b), who used a similar method to investigate precarious manhood. We asked participants to respond to a list of straightforward statements of opinion suggesting that either heterosexual or gay identity was fragile (depending on condition). We predicted that participants would more strongly endorse statements about the fragility of heterosexual identity than the fragility of gay identity. Results from Study 2a and 2b suggest that heterosexual identity is more fragile than gay identity, regardless of gender. Accordingly, we specifically hypothesized that no interaction of condition with either target or participant gender would eliminate or reverse the fragile heterosexuality effect.

\section{Methods}

\section{Participants and Recruitment}

Five hundred two British people (248 women, 252 men, $\left.M_{\text {age }}=37.83, S D=12.47\right)$ were recruited via Prolific - an online participant recruitment platform. Each participant completed the online experiment in exchange for a fee ( $£ 0.90$ each). After exclusions (see pre-registration), we were left with an effective sample of 489 participants (243 women, 246 men, $M_{\text {age }}=37.92, S D=12.45$ ). The full dataset is available in ESM 5.

\section{Design and Procedure}

Participants were randomly assigned to complete one of the four versions of the questionnaire. Depending on the condition, participants either indicated their agreement with statements expressing the idea that heterosexual identity was fragile in (1) men or (2) women, or that gay identity was fragile in (3) men or (4) women. Therefore, our experiment was a 2 (Condition: fragile heterosexual identity items vs. fragile gay identity items) $\times 2$ (Target gender: male vs. female) $\times 2$ (Participant gender: men vs. women) between-participants factorial design.

All participants completed a questionnaire containing a list of 21 statements of opinion, which included 7 distractor items. These items inquired about controversial topics that were not related to our hypotheses. The 14 critical items that expressed ideas about the fragility of a particular sexual orientation were randomly distributed throughout the questionnaire. These statements were developed for this study and derived from prior qualitative work on sexual orientation (Anderson, 2008; Messner, 2004).

The 14 statements related to the fragility of heterosexual or gay identity (in men or women) provided participants with statements such as: "It only takes one gay experience for a man to no longer be straight" versus "It only takes one straight experience for a man to no longer be gay"; "It only takes one lesbian experience for a woman to no longer be straight" versus "It only takes one straight experience for a woman to no longer be a lesbian". The full list of all 14 items for all 4 conditions is included in the Appendix. Participants responded to all items on a 7-point Likert scale ranging from $1=$ strongly disagree to $7=$ strongly agree. The 14 items related to fragile sexual orientation formed a reliable scale $(\alpha=.81$, CI [0.78, 0.83]), even when different subgroups of condition and target gender were considered: fragile heterosexual identity in men $(\alpha=.80$, CI [0.74, $0.85])$, fragile gay identity in men $(\alpha=.79$, CI [0.73, $0.84])$, fragile heterosexual identity in women $(\alpha=.78$, CI $[0.72,0.84])$, and fragile gay identity in women $(\alpha=.78$, CI $[0.72,0.84])$.

\section{Results}

An ANCOVA was conducted with mean agreement to the fragility of sexual orientation as the dependent variable; 
Table 3. Results for the ANCOVA done for Study 3

\begin{tabular}{|c|c|c|c|c|c|c|}
\hline Effects & $N$ & $F$ & $p$ value & $\eta^{2}$ & $\beta$ & $\mathrm{Cl}$ \\
\hline Condition & 481 & 48.58 & $<.001$ & .093 & -0.630 & {$[-0.89,-0.37]$} \\
\hline Participant Gender & 481 & 3.60 & .05 & .007 & -0.103 & {$[-0.36,0.16]$} \\
\hline Target Gender & 481 & 14.19 & $<.001$ & .029 & -0.524 & {$[-0.78,-0.26]$} \\
\hline Condition $\times$ Target Gender & 481 & 14.95 & $<.001$ & .030 & 0.401 & {$[0.037,0.76]$} \\
\hline Participant Age & 481 & 1.10 & .29 & .002 & -0.003 & {$[-0.00,0.002]$} \\
\hline Condition $\times$ Participant Gender & 481 & 0.35 & .55 & .001 & -0.194 & {$[-0.55,0.18]$} \\
\hline Participant Gender $\times$ Target Gender & 481 & 1.05 & .31 & .002 & 0.028 & {$[-0.34,0.39]$} \\
\hline Condition $\times$ Participant Gender $\times$ Target Gender & 481 & 0.66 & .42 & .001 & 0.214 & {$[-0.30,0.73]$} \\
\hline
\end{tabular}

Note. Residuals of the dependent variable were normally distributed (skewness and kurtosis between \pm 0.85 ). Values in bold indicate significant effects.

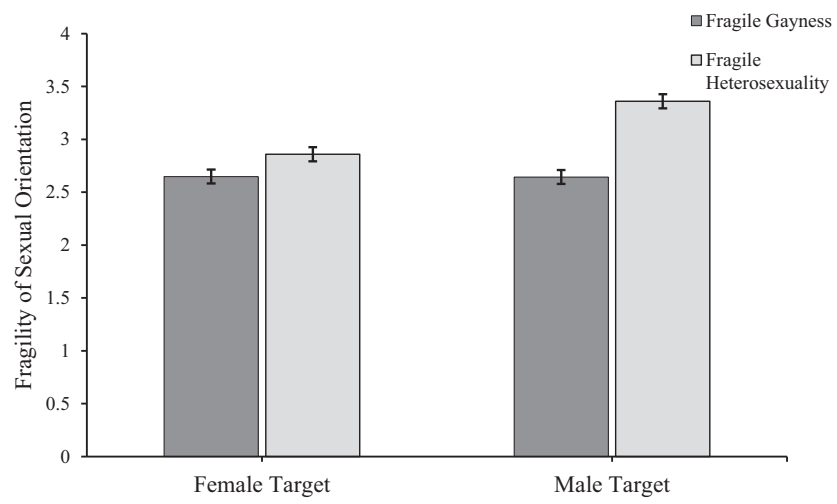

Figure 3. Agreement to fragility of sexual orientation fragility (fragile gayness vs. fragile heterosexuality) depending on target's gender (Study 3). Error bars represent standard errors.

condition, participant gender, and target gender as fixed factors, and participants age as a covariate. As expected, we found the hypothesized main effect of the condition. Participants more strongly agreed with statements about the fragility of heterosexual identity $(M=3.11, S D=0.78)$, than with statements about the fragility of gay identity $(M=2.64, S D=0.71)$. Additionally, participants' gender marginally affected the agreement with statements about the fragility of sexual orientation. Compared to women $(M=2.81, S D=0.76)$, men expressed higher agreement with the items $(M=2.93, S D=0.80)$. Target gender significantly influenced agreement with statements about sexual orientation fragility. Participants agreed more strongly with statements about a male target $(M=3.00, S D=0.87)$ than with statements about a female target $(M=2.75, S D=0.67)$. In support of our central hypothesis, although there was also a significant interaction of condition and target gender, this did not reverse or eliminate the fragile heterosexuality effect. When responding to questions about female targets as well as male targets, there was more agreement with statements about the fragility of heterosexual identity than about the fragility of gay identity (female target: $t(243)=-2.52, p=.012, d=0.32$, CI $[-0.38,-0.47]$,
$M=2.86, S D=0.63$ vs. $M=2.65, S D=0.70$; and male target: $t(243)=-7.16, p<.001, d=0.91$, CI $[-0.92$, -0.52 ], $M=3.36, S D=0.85$ vs. $M=2.64, S D=0.73$ ). Neither participant's age, nor any of the other two-orthree-way interactions had a significant effect on the dependent variable (all $p$ 's $>.30$ ). See Table 3 for detailed stats and Figure 3 for a graphical representation of results.

\section{Study 4}

Results from Studies 1, 2a, 2b, and 3 supported the hypotheses that heterosexual identity is perceived to be more fragile than gay identity and that this effect persists for both men and women perceivers and male and female targets. The aim of Study 4 was therefore to understand what drives the asymmetry in perceptions of sexual orientation, including possible moderators such as estimates of gay/lesbian population, prejudice against gay/lesbian people, social dominance orientation, right-wing authoritarianism, and contact between groups. We predicted that, as heterosexuality becomes less of the "social norm" (i.e., estimates of gay/lesbian population increase), there would be less asymmetrical perceptions between heterosexual identity and gay identity. Specifically, fragility perceptions of heterosexual identity should decrease, while fragility perceptions of gay identity should increase.

To determine the necessary sample size for this study, we used the sample size from Study 1, which revealed a relatively large effect size for the difference in perceived fragility of heterosexual versus gay identity, $\eta^{2}=.089$ (Lakens, 2013). In this case, we used Ledgerwood's (2019) rule of thumb to perform our power calculations, as $G^{*}$ Power can make distorted estimates for moderations (GinerSorolla, 2018; Ledgerwood, 2019). This rule depends on the type of results expected for the interaction. If a reversal is expected for the new condition, one should use a cell $n$ equal to the original study (total $N=2 \times$ the original). When a knockout effect is expected for the new condition, the cell 
size should be double that of the original study (total $N=4$ $x$ the original). Finally, if the effect of the new condition is expected to attenuate the difference by $50 \%$, one should use a cell $\mathrm{n}$ that is seven times that of the original study $(N=14 \times$ the original). Therefore, the projected sample size needed to test a potential moderation in a $2 \times 2$ betweensubjects factorial design would be 1,176 (84 participants to test the difference between heterosexual and gay identities fragility $\times 14$ ). All parameters for this study were preregistered via AsPredicted.org (https://aspredicted.or/b52ca. pdf). Analyses reported here are those preregistered.

\section{Methods}

\section{Participants and Recruitment}

Our total sample consisted of 1,277 white, heterosexual, British people (men $N=619$ and women $N=658$ ), who were recruited via prolific (https://prolific.ac). Participants were paid $£ 0.90$ in total for their participation. After exclusions our total sample size was 1197 (men's $N=579, M_{\text {age }}=$ $37.82, S D=12.78$; women's $N=617, M_{\text {age }}=38.07, S D=$ 11.78). The full dataset is available in ESM 6.

\section{Design and Procedure}

This study consisted of between-participant design. Each participant was randomly assigned to one of the two conditions (fragile heterosexual identity vs. fragile gay identity). As in Study 3, participants indicated their level of agreement (7-point-Likert scale) with 14 statements related to each condition, however, statements were gender-neutral (see Appendix for the complete list).

First, participants answered questions related to one of the two conditions, with 14 items related to either fragile heterosexual identity $(\alpha=.77$, CI $[0.75,0.80])$ or fragile gay identity $(\alpha=.79$, CI $[0.77,0.82])$. Then participants were presented with questions related to each moderator. In terms of estimates of gay/lesbian population participants answered two questions: "1. What percentage of the overall population would you estimate is actually gay or lesbian?" and "2. What percentage of the overall population would you estimate is openly either gay or lesbian?" (Martinez et al., 2008).

Social dominance orientation was measured with 10 items (four items from Pratto et al., 2013; and six items from Pratto et al., 1994). For right-wing authoritarianism, participants indicated their level of agreement with 15 statements (Zakrisson, 2005). Similarly, prejudice against gay/ lesbian people was measured using an agreement with 5 statements (Herek, 1988). In terms of contact quantity, participants answered 4 questions (Van Dick et al., 2004). If participants did not have any contact with gay/lesbian people they were not asked about contact quality. Conversely, if participants did have contact with gay/lesbian people, they answered how pleasant was this interaction (Schwartz et al., 2001). Overall, all moderators showed high internal consistency (estimates of gay/lesbian population $r=.80$; social dominance orientation $(\alpha=.92$, CI $[0.91,0.92])$; right-wing authoritarianism $(\alpha=.81, \mathrm{CI}[0.79,0.83])$; prejudice against gay/lesbian people $(\alpha=.86$, CI [0.84, $0.87])$, and contact quantity ( $\alpha=.79$, CI [0.77, 0.81]). Finally, participants responded to 5 demographic questions (gender, age, ethnicity, sexual orientation, and religion). Full lists of all items used in this study can be found in the Appendix.

\section{Results}

We ran an ANCOVA, with (fragility of heterosexual identity vs. fragility of gay identity) and participants' gender (women vs. men) as independent variables and fragility of sexual orientation as the dependent variable. Along with age, all moderators (estimates of gay/lesbian population, social dominant orientation, right-wing authoritarianism, prejudice against gay/lesbian people, and contact) were included as covariates. Our model was customized to include all possible interactions between condition and moderators.

There was a significant main effect of condition replicating findings from Studies 1, 2a, 2b, and 3. Participants agreed more strongly with statements about the fragility of heterosexual identity $(M=3.06, S D=0.68)$, than about the fragility of gay identity $(M=2.69, S D=0.71)$. Women participants showed significantly lower perceptions of fragility of sexual orientation compared to men $(M=2.76, S D=$ 0.68 vs. $M=3.00, S D=0.75$. Additionally, older participants had significantly lower fragility perceptions of sexual orientation. Three out of the six possible moderators had significant main effects on the fragility of sexual orientation: estimates of gay/lesbian population, social dominance orientation, and prejudice against gay/lesbian people. Participants reporting high estimates of gay/lesbian population, higher social dominance orientation, and more prejudice against gay/lesbian people, showed higher perceptions of fragility. No significant effects were found for any other moderators (all $p$ 's $>.076$ ). Furthermore, conditions (fragile heterosexual identity vs. fragile gay identity) significantly interacted with estimates of the gay lesbian population, as well as with social dominance orientation. None of the other interactions were significant (all p's > .31). See Table 4 for detailed statistical results.

To further probe the interactions between (1) condition and estimates of gay lesbian population and (2) condition and social dominant orientation, we ran two moderation analyses via the PROCESS macro Model 1 with pre-standardized variables, $95 \%$ confidence intervals 
Table 4. Results for the ANCOVA done for Study 4

\begin{tabular}{|c|c|c|c|c|c|c|}
\hline Effects & $N$ & $F$ & $p$ value & $\eta^{2}$ & $\beta$ & $\mathrm{Cl}$ \\
\hline Condition & 907 & 10.22 & .001 & .011 & 1.184 & {$[0.418,1.939]$} \\
\hline Participant's Gender & 907 & 18.32 & $<.001$ & .020 & 0.162 & {$[0.043,0.288]$} \\
\hline Participant's Age & 907 & 6.47 & .011 & .007 & -0.003 & {$[-0.008,0.002]$} \\
\hline SDO & 907 & 15.16 & $<.001$ & .017 & 0.185 & {$[0.097,0.273]$} \\
\hline Estimates Gay/Lesbian population & 907 & 5.05 & .025 & .006 & 0.009 & {$[0.003,0.014]$} \\
\hline Prejudice Against Gay/Lesbian & 907 & 49.48 & $<.001$ & .002 & 0.028 & {$[0.120,0.245]$} \\
\hline Estimates Gay/Lesbian Population $\times$ Condition & 907 & 4.40 & .036 & .005 & -0.008 & {$[-0.016,-0.001]$} \\
\hline SDO $\times$ Condition & 907 & 4.71 & .030 & .005 & -0.132 & {$[-0.252,-0.013]$} \\
\hline Contact Quality & 907 & 1.78 & .18 & .002 & -0.009 & {$[-0.801,0.065]$} \\
\hline RWA & 907 & 3.34 & .07 & .004 & 0.046 & {$[-0.038,0.131]$} \\
\hline Contact Quantity & 907 & 0.00 & .98 & .001 & -0.008 & {$[-0.052,0.036]$} \\
\hline Participant's Gender $\times$ Condition & 907 & 0.37 & .54 & .001 & 0.055 & {$[-0.122,0.232]$} \\
\hline Prejudice Against Gay/Lesbian $\times$ Condition & 907 & 1.51 & .21 & .002 & -0.054 & {$[-0.141,0.032]$} \\
\hline RWA $\times$ Condition & 907 & 0.12 & .74 & .000 & 0.021 & {$[-0.101,0.143]$} \\
\hline Contact Quantity $\times$ Condition & 907 & 0.24 & .62 & .000 & 0.015 & {$[-0.046,0.076]$} \\
\hline Contact Quality $\times$ Condition & 907 & 0.94 & .33 & .001 & -0.047 & {$[-0.142,0.048]$} \\
\hline
\end{tabular}

Note. Residuals for this model were normally distributed (skewness and kurtosis \pm 0.94 ). Values in bold indicate significant effects. RWA = Right-Wing Authoritarianism; SDO = Social Dominant Orientation

Table 5. Results for the estimates of gay/lesbian population (EGLP) Moderation done for Study 4

\begin{tabular}{|c|c|c|c|c|c|c|c|}
\hline & $R$ & $R^{2}$ & MSE & $F$ & $d f_{1}$ & $d f_{2}$ & $p$ \\
\hline \multirow[t]{2}{*}{ Model } & 0.27 & 0.076 & 0.49 & 32.21 & 3 & 1,177 & $<.001$ \\
\hline & & Coeff & SE & $t$ & $p$ & $\mathrm{LLCl}$ & ULCl \\
\hline Condition & & -0.621 & 0.084 & -7.326 & $<.001$ & -0.787 & -0.455 \\
\hline EGLP & & -0.016 & 0.005 & -2.998 & .002 & -0.027 & -0.005 \\
\hline Condition $\times$ EGLP & & 0.011 & 0.003 & 3.284 & .001 & 0.005 & 0.018 \\
\hline Moderator values & & Effect & SE & $t$ & $p$ & LLCl & ULCl \\
\hline $9 \%$ & & -0.518 & 0.059 & -8.739 & $<.001$ & -0.635 & -0.402 \\
\hline $20.50 \%$ & & -0.387 & 0.041 & -9.467 & $<.001$ & -0.468 & -0.307 \\
\hline $32.94 \%$ & & -0.246 & 0.057 & -4.297 & $<.001$ & -0.358 & -0.133 \\
\hline
\end{tabular}

Note. Values in bold indicate significant effects.

(CIs), and 1,000 bias-corrected bootstrap samples. Mean fragility of sexual orientation was included as the dependent variable and condition were included as the independent variable. Estimates of the gay/lesbian population and social dominant orientation were included as moderators in separate analyses.

The model involving estimates of the gay/lesbian population was significant. Condition, estimates of the gay/lesbian population, and the interaction between these two variables were significant predictors of fragility beliefs. When the estimates of the gay/lesbian population were low (i.e., 9\%), the difference between fragility perceptions between heterosexual identity and gay identity was greater, smaller at average estimates (i.e., 20.5\%), and smallest at higher (i.e., 32.9\%) estimates of the gay/lesbian population (see Table 5 for complete statistics and Figure 4 for a graphical representation).

The model involving the social dominance orientation model was significant. Although there was no main effect of social dominance orientation in this model, there was a significant effect of condition and a significant interaction between these variables. It should be noted that this moderation did not help explain the existing asymmetry in perceptions of sexual orientation fragility as social dominance orientation increased fragility perceptions for both heterosexual identity and gay identity (see Table 6 for complete statistics and Figure 5 for a graphical representation). 


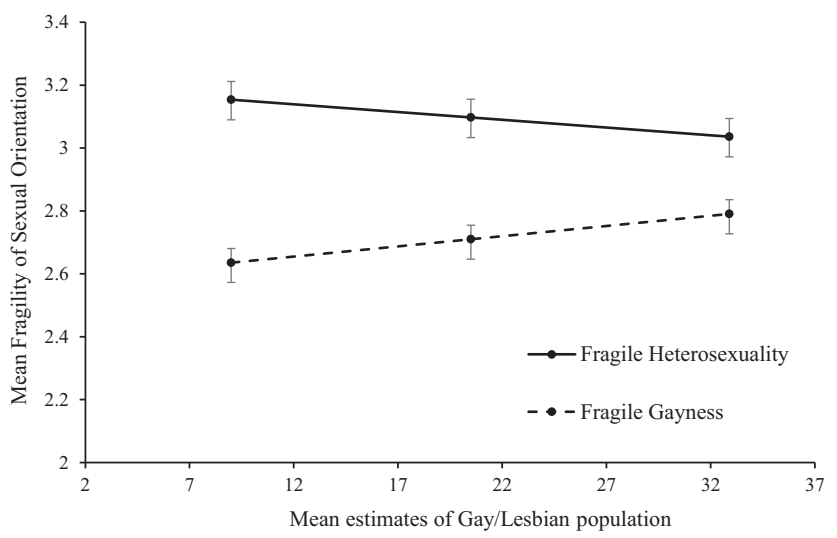

Figure 4. Moderation effect of estimates if gay/lesbian population on fragility of sexual orientation (Study 4). Error bars represent standard errors.

\section{General Discussion}

This current research investigated whether there were asymmetrical fragility perceptions between heterosexual identity and gay identity. Specifically, and in line with previous results from different populations, we predicted that heterosexual identity would be perceived as more fragile than gay identity. We also investigated a range of possible moderators of this effect, including perceiver gender, target gender, attitudes, experiences, individual differences in intergroup orientations, and estimates of population size. It is important to note that the scale developed to measure the fragility of sexual orientation was reliable for Studies 3 and 4, which constitutes a further advance in trying to understand this phenomenon.

The results of all studies showed support for our central prediction: incongruous behaviors have a larger effect on perceptions of someone's heterosexual identity than on perceptions of someone's gay identity, hence heterosexual identity is more fragile (easily compromised) than gay identity.

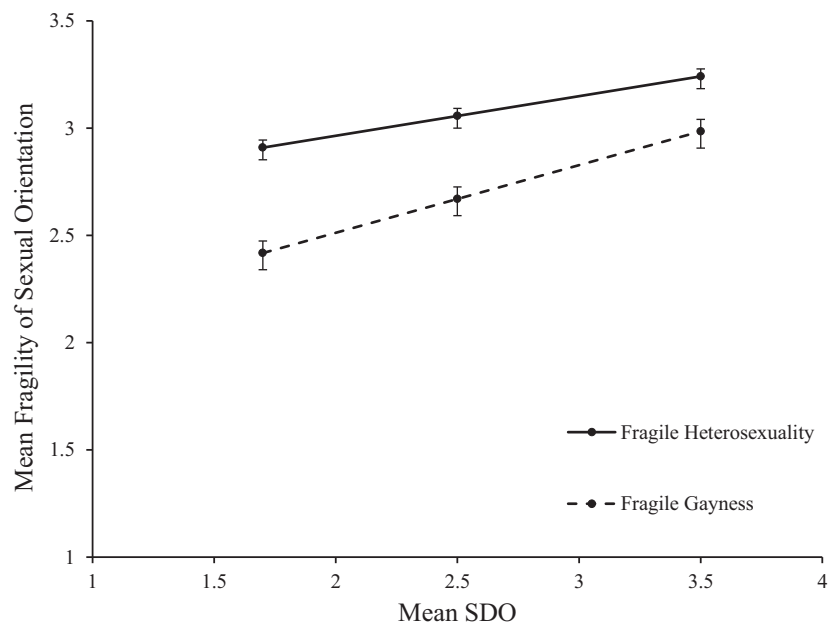

Figure 5. Moderation effect of mean SDO on fragility of sexual orientation (Study 4). Error bars represent standard errors.

The findings were replicated across different methodologies; including perceptions of the sexual orientation of a target who engaged in behavior that contradicted his disclosed sexual orientation (Study 1), free-response indications of behaviors required to undermine the heterosexual and gay identities of both male and female targets (Studies 2a and $2 b$ ), agreement with statements related to male/female targets of different sexual orientations (Study 3), and agreement with gender-neutral statements about the fragility of heterosexual and gay identities (Study 4). The consistency of findings across samples and methodologies, provide strong evidence for the robustness of the effects found here, showing that it was not limited to a particular mode of response or type of stimulus. Regardless of how or with whom it was investigated, our participants consistently indicated a belief that heterosexual identity was more fragile than gay identity.

This is the first study to unequivocally demonstrate that the fragility of heterosexuality occurs for both men and

Table 6. Results for the Social Dominant Orientation (SDO) Moderation done for Study 4

\begin{tabular}{|c|c|c|c|c|c|c|c|}
\hline & $R$ & $R^{2}$ & MSE & $F$ & $d f_{1}$ & $d f_{2}$ & $p$ \\
\hline \multirow[t]{2}{*}{ Model } & 0.38 & 0.15 & 0.45 & 68.14 & 3 & 1,185 & $<.001$ \\
\hline & & Coeff & SE & t & $p$ & LLCl & ULCI \\
\hline Condition & & -0.714 & 0.134 & -5.310 & $<.001$ & -0.978 & -0.450 \\
\hline SDO & & 0.054 & 0.077 & 0.700 & .484 & -0.096 & 0.204 \\
\hline Condition $\times$ SDO & & 0.131 & 0.048 & 2.699 & .007 & 0.036 & 0.226 \\
\hline Moderator values & & Effect & SE & $t$ & $p$ & $\mathrm{LLCl}$ & ULCl \\
\hline 1.7 & & -0.492 & 0.061 & -8.118 & $<.001$ & -0.610 & -0.373 \\
\hline 2.5 & & -0.387 & 0.039 & -9.714 & $<.001$ & -0.465 & -0.309 \\
\hline 3.5 & & -0.256 & 0.057 & -4.516 & $<.001$ & -0.367 & -0.145 \\
\hline
\end{tabular}

Note. Values in bold indicate significant effects. 
women. Prior research either did not consider men and women separately (Duran et al., 2007; Flanders \& Hatfield, 2014) or failed to find the effect for women (Mize \& Manago, 2018). We also show that the fragility effect persists even when behaviors under discussion are standardized across sexual orientations. Thus, our results add meaningfully to prior studies of asymmetrical perceptions of sexual orientations (Mize \& Manago, 2018; Duran et al., 2007; Flanders \& Hatfield, 2014) by establishing the reliability of this effect, with both men and women, in a different population, through larger samples, and with multiple divergent methods.

We also extend past research by testing different plausible moderators of this effect. In line with our predictions, higher estimates of the gay/lesbian population reduced the asymmetry in fragility perceptions between heterosexual identity and gay identity. It is also noteworthy that several other plausible variables - including anti-gay prejudice, contact with gay and lesbian individuals, and right-wing authoritarianism - did not moderate the fragile heterosexuality effect. Following the social normativity model (Monteith et al., 1996; Zarate \& Smith, 1990), disparities in summary information about a reference group (estimates of the gay/lesbian population), moderated the different fragility perceptions between heterosexual identity and gay identity. The results observed here show that when gay identity becomes less "deviant" and more prevalent within an individual's perceptions of society, heterosexual and gay identities are perceived to be more similar in terms of fragility. These results may reflect an adjustment in status perceptions between groups. That is, people who perceive more widespread gay identities within their contexts also perceive a smaller gap between the status of heterosexual people and gay people.

Beyond the specific domain of sexual identities our results parallel with evidence from a variety of majorityminority distinctions that are asymmetrically perceived, including distinctions based on race and gender (Bosson \& Vandello, 2011; Duran et al., 2007; Flanders \& Hatfield, 2014; Ho et al., 2013; Khanna, 2010; Vandello et al., 2008). For instance, the criteria for inclusion in racial categories typically differs between majority group membership (i.e., White) and minority group membership (i.e., Black). Reflecting a similar "one-drop rule," studies have shown that the presence of a single Black ancestor can be sufficient for a person to be perceived as Black, but the presence of a single White ancestor is not sufficient for a person to be perceived as White (Ho et al., 2013; Khanna, 2010). A similar pattern is evident in the context of gender identities. Research on precarious (fragile) manhood has shown that manhood is a status that is difficult to attain and maintain and can be easily lost through displays of un-manly behaviors. Womanhood, on the other hand, is a status that is ascribed rather than achieved, and is contingent on biological transformation rather than confirmation through one's own behavior (Bosson \& Vandello, 2011; Bosson et al., 2009; Vandello et al., 2008).

We acknowledge that the asymmetry in fragility between heterosexual identity and gay identity may be explained by an effect of cultural defaults on information diagnosticity. In other words, engaging in heterosexual behavior (e.g., visiting a non-sexual orientation coded bar) is not diagnostic of sexual orientation, but visiting a gay bar is, simply because it must be actively sought out among the myriad non-sexual orientation coded bar options. Relatedly, engaging in openly gay behavior may be considered more costly, as it comes with the potential for stigmatization. Thus, one might reasonably assume that even individuals who are gay might refrain from certain behaviors, making gay behavior more diagnostic.

However, if this were the case, the effect of fragile heterosexuality should have been moderated by participants' levels of anti-gay bias, but this moderation was not significant. Also, were the fragile heterosexuality effect merely due to differences in assumed diagnosticity, we should not have found differences in the strength of the effect for men and women targets, which we did. Furthermore, the effect should have disappeared when we exclusively considered statements related to thoughts (supplementary analyses, see ESM 4). However, when we investigated this alternative explanation by excluding statements related to behavior from our fragility scale, we still found that heterosexual identity was perceived as more fragile than gay identity. These results strengthen our argument in support of the asymmetrical fragility perceptions between heterosexual and gay identities.

It should be noted that in spite of the higher fragility of heterosexual identity relative to gay identity observed across all studies and sub-groups, including men and women perceivers, the asymmetry in fragility perceptions between heterosexual identity and gay identity was larger for male compared to female targets (Study 3). These results could be attributed to women's (actual or perceived) sexual fluidity. Several studies have concluded that women's sexual orientation is significantly more dynamic than that of men (Diamond, 2000; Kinnish et al., 2005). In fact, Kinnish and colleagues (2005) found that women, describe and experience their sexuality in continuous and ever-evolving terms, whereas men describe their sexual orientation as static and unchanging. Additionally, findings from Chandra et al. (2011) showed that the rate of men who identify themselves as bisexual was significantly lower compared to women. Accordingly, we believe that having less fluid sexuality (less gay/lesbian experiences) may be more indicative of men's sexual orientation than it would be for women. To the extent that perceivers hold implicit 
theories of sexuality that are consistent with this picture, they are likely to judge male behavior as more diagnostic of sexual preferences than female behavior. Of course, it could equally be argued that just as heterosexual identity is more normative than gay identity, maleness is more normative than femaleness. Accordingly, the particular fragility of male heterosexual identity might reflect the intersection of these two categories.

The asymmetry in fragility perceptions between heterosexual and gay identities was quite robust, however, it is also the case that women participants generally perceived sexual categories to be less fragile than men participants did (Studies 3 and 4). This finding parallels findings from previous research on attitudes toward gay/ lesbian people, in which women have been found to hold less negative attitudes toward gay/lesbian people compared to men (for a review see Whitley \& Kite, 1995). Men are more likely to believe that gay identity is a discrete, dichotomous category, than women (Haslam \& Levy, 2006), and are more likely than women to categorize themselves as "gay" based on past same-sex sexual experience (whereas for women, past experience does not automatically result in identification: Kinnish et al., 2005). Women seem to be less strict about defining the boundaries of sexual orientation to which they assign themselves (and others). The effects of perceiver gender might again reflect that women's categorization processes are more flexible than those of men.

\section{Limitations and Future Studies}

The current research focused on asymmetrical fragility perceptions of heterosexual and gay identities. The concept of bisexuality or sexual fluidity was not explored. As this was the first representative quantitative exploration of fragile heterosexuality within a British population, this focus was necessary. However, perceptions of bisexuality and sexual fluidity are an important area of relevant future research. Some conceptions of bisexuality highlight the spectrum of possible gender identities and sexual attractions, undermining fundamental assumptions inherent in the definitions of both heterosexual and gay identities (Moore \& Norris, 2005; Peery \& Bodenhausen, 2008; Savin-Williams, 2016). Thus, future research on differences in perceptions of sexual orientation should explore a broader range of categories. For instance, participants could be given the option to assign a target to the bisexual or sexually fluid category. Relatedly, Peery and Bodenhausen (2008) found that the hypodescent effect for racial minorities decreases when participants have more time to categorize a target. Thus, a similar effect might occur for judgments of sexual orientation; participants may be more inclined to consider fluid sexuality or bisexuality when given more time to process a target's behaviors.

Another consideration is that earlier studies have revealed a stereotype that gay people are more promiscuous than heterosexuals (e.g., Pinsof \& Haselton, 2017). It is possible that the fragile heterosexuality effect found here may reflect this. That is, when gay people engage in incongruous sexual behavior, it may be more easily dismissed due to being understood as stereotype-consistent promiscuity and broadly directed sexual desire. Conversely, when heterosexual people engage in incongruous sexual behavior its observers tend to engage in more thorough processing of the implications for their sexual orientation. While this would not undermine the fragile heterosexuality effect, future research should investigate whether, and to what extent, the effect may be explained by relevant stereotypes of promiscuity concerning heterosexual people and sexual minorities.

Additionally, our study revealed that higher estimates of the gay/lesbian population lead to less differences in fragility perceptions between heterosexuals and gays. We suggest that these results may reflect participants' change in status perceptions of these two groups. This contention should be tested empirically in future studies. For example, heterosexual participants could be primed with a scenario where the status of gay people is either more similar to or significantly different from the status of heterosexual people.

The studies reported here were carried out entirely in the UK using heterosexual, White, British participants. In spite of Britain being more open-minded and less prejudiced against sexual minorities than the USA (Mazzuca, 2004), our results parallel with those found for an American population (Mize \& Manago, 2018). However, there is no evidence yet that the fragile heterosexuality effect transcends a particular Western cultural milieu. Indeed, as the effect appears to depend on estimates of gay/lesbian populations, it is reasonable to expect variation between nations based on the status of sexual minorities in each specific location. Future international and cross-cultural research would be important for exploring these hypotheses. Perhaps, exploring the differences between countries with a known-record of prejudice against sexual minorities, like Jamaica (Borras-Guevara \& West, 2020; West \& Cowell, 2015) and a more egalitarian country like the UK. Targeted replications could also investigate whether sexual minorities also perceive heterosexual identity to be more fragile than gay identity.

Being perceived as a sexual minority implies being stereotyped and discriminated against, hence our focus was to understand where asymmetrical perceptions of the fragility of sexual orientation come from. However, we acknowledge that a very important step toward tackling 
prejudice against the LGBTQ community is to understand the consequences of these asymmetries too. Future research should study experimentally whether higher fragility leads to more negative attitudes/behaviors (e.g., violence) toward sexual minorities.

\section{Conclusions}

Prior research and socio-political commentary have alluded to the asymmetric nature of fragility perceptions of sexual orientation. The current research extended that work by (a) demonstrating this fragility with a variety of quantitative methods; (b) clarifying that it applies across genders and; (c) finding evidence that these beliefs are moderated by estimates of the gay/lesbian population. The assigned status of heterosexual was shown to be more difficult to maintain than the status of being gay. Normalization of the gay/lesbian population predicted smaller differences in fragility perceptions between heterosexual identity and gay identity. These results remind us that the definition of a social category is not merely linguistic practicality or balanced description of symmetrically understood states. Rather, categories may also reflect, and inform, our perceptions and treatment of the groups they describe.

\section{Electronic Supplementary Material}

The electronic supplementary material is available with the online version of the article at https://doi.org/ 10.1027/1864-9335/a000444

ESM 1. Supplementary analyses (not included in preregistration)

ESM 2. Study 1 dataset

ESM 3. Study 2a dataset

ESM 4. Study $2 b$ dataset

ESM 5. Study 3 dataset

ESM 6. Study 4 dataset

\section{References}

Anderson, E. (2005). In the game: Gay athletes and the cult of masculinity. SUNY Press.

Anderson, E. (2008). "Being masculine is not about who you sleep with": Heterosexual athletes contesting masculinity and the one-time rule of homosexuality. Sex Roles, 58(1-2), 104-115. https://doi.org/10.1007/s11199-007-9337-7

Anderson, E., Adams, A., \& Rivers, I. (2012). "I kiss them because I love them": the emergence of heterosexual men kissing in British institutes of education. Archives of Sexual Behaviour, 41, 421-430. https://doi.org/10.1007/s10508.010.9678.0
Borras-Guevara, M. L., \& West, K. (2020). Masculinity threat: Understanding why Jamaican men report more anti-gay prejudice than Jamaican women. Journal of Gender Studies, 1-14. https://doi.org/10.1080/09589236.2020.1842178

Bosson, J., \& Vandello, J. (2011). Precarious manhood and its links to action and aggression. Current Directions in Psychological Science, 20(2), 82-86. https://doi.org/10.1177/0963721411402669

Bosson, J., Vandello, J. A., Burnaford, R., Weaver, J., \& Arzu Wasti, S. (2009). Precarious manhood and displays of physical aggression. Personality \& Social Psychology Review, 35(5), 623-634. https://doi.org/10.1177/0146167208331161

Chandra, A., Mosher, W., Copen, C., \& Sionean, C. (2011). Sexual behaviour, sexual attraction, and sexual identity in the United States: Data from the 2006-2008 National Survey of Family Growth. National Health Statistics Reports, 3(36), 1-36. https:// doi.org/10.1007/978-94-007-5512-3_4

Chen, J., de Paula Couto, M., Sacco, A., \& Dunham, Y. (2018). To be or not to be (black or multiracial or white) cultural variation in racial boundaries. Social Psychological and Personality Science, 9(7), 763-772. https://doi.org/10.1177/1948550617725149

Costa-Lopes, R., Vala, J., \& Judd, C. (2012). Similarity and dissimilarity in intergroup relations: Different dimensions, different processes. Revue Internationale de Psychologie Sociale, 25(1), 31-65. https://www.cairn.info/revue-internationale-depsychologie-sociale-2012-1-page-31.htm

Dhont, K., \& Van Hiel, A. (2011). Direct contact and authoritarianism as moderators between extended contact and reduced prejudice: Lower threat and greater trust as mediators. Group Processes \& Intergroup Relations, 14(2), 223-237. https://doi. org/10.1177/1368430210391121

Diamond, L. (2000). Sexual identity, attractions, and behaviour among young sexual-minority women over a 2-year period. Developmental Psychology, 36(2), 241-250. https://doi.org/ 10.1037/0012-1649.36.2.241

Dovidio, J., Gaertner, S., Isen, A., \& Lowrance, R. (1995). Group representations and intergroup bias: Positive affect, similarity, and group size. Personality and Social Psychology Bulletin, 21(8), 856-865. https://doi.org/10.1177/0146167295218009

Duran, A., Renfro, L., Waller, M., \& Trafimow, D. (2007). Perceptions of sexual orientation: A hierarchically restrictive trait. Sex roles, 57(9-10), 763-773. https://doi.org/10.1007/s11199-0079293-2

EuroClinix. (2018). EuroClinix survey: How many gay and bisexual people are in the UK? https://www.pinknews.co.uk/2018/11/ 16/lgbt-stats-gay-bisexual-uk/

Flanders, C., \& Hatfield, E. (2014). Social perception of bisexuality. Psychology \& Sexuality, 5(3), 232-246. https://doi.org/10.1080/ 19419899.2012.749505

Giner-Sorolla, R. (2018, April 6). JESP editorial guidelines. https:// www.journals.elsevier.com/journal-of-experimentalsocialpsychology/news/announcement-of-new-policiesfor-2018-at-jesp

Glick, P., Gangl, C., Gibb, S., Klumpner, S., \& Weinberg, E. (2007) Defensive reactions to masculinity threat: More negative affect toward effeminate (but not masculine) gay men. Sex Roles, 57(1-2), 55-59. https://doi.org/10.1007/s11199-007-9195-3

Harwood, J., Hewstone, M., Paolini, S., \& Voci, A. (2005). Grandparent-grandchild contact and attitudes toward older adults: Moderator and mediator effects. Personality and Social Psychology Bulletin, 31(3), 393-406. https://doi.org/10.1177/ 0146167204271577

Haslam, N., \& Levy, S. (2006). Essentialist beliefs about homosexuality: Structure and implications for prejudice. Personality and Social Psychology Bulletin, 32(4), 471-485. https://doi.org/ $10.1177 / 0146167205276516$ 
Herek, G. (1988). Heterosexuals' attitudes toward lesbians and gay men: Correlates and gender differences. Journal of Sex Research, 25(4), 451-477. https://doi.org/10.1080/00224498809551476

Ho, A., Sidanius, J., Cuddy, A., \& Banaji, M. (2013). Status boundary enforcement and the categorization of black-white biracials. Journal of Experimental Social Psychology, 49(5), 940-943. https://doi.org/10.1016/j.jesp.2013.04.010

Ho, A., Sidanius, J., Levin, D., \& Banaji, M. (2011). Evidence for hypodescent and racial hierarchy in the categorization and perception of biracial individuals. Journal of Personality and Social Psychology, 100(3), 492-506. https://doi.org/10.1037/ a0021562

Khanna, N. (2010). "If your're half Black, you're just Black": Reflected appraisals and the persistence of the One-Drop Rule. The Sociological Quarterly, 51(1), 96-121. https://doi.org/ 10.1111/j.1533-8525.2009.01162.x

Kinnish, K., Strassberg, D., \& Turner, C. (2005). Sex differences in the flexibility of sexual orientation: A multidimensional retrospective assessment. Archives of Sexual Behaviour, 34(2), 173183. https://doi.org/10.1007/s10508-005-1795-9

Lakens, D. (2013). Calculating and reporting effect sizes to facilitate cumulative science: A practical primer for $t$-tests and ANOVAs. Frontiers in Psychology, 4, Article 863. https://doi. org/10.3389/fpsyg.2013.00863

Ledgerwood, A. (2019). New developments in research methods. In R. Baumeister \& E. Finkel (Eds.), Advanced social psychology (pp. 39-61). Oxford University Press.

Lee, C., \& Kwan, P. (2014). The trans panic defense: masculinity, heteronormativity, and the murder of transgender women. Hastings Law Journal, 66(1), 77-132. https://heinonline.org/HOL/ LandingPage?handle=hein.journals/hastlj66\&div=6\&id=\&page

Lee, H. (2006). Three sentenced to prison in Araujo slaying. San Francisco Gate, 1-5. http://www.sfgate.com/news/article/ Three-sentenced-to-prison-in-Araujo-slaying-2542846.php

Martinez, M., Wald, K., \& Craig, S. (2008). Homophobic innumeracy? Estimating the size of the gay and lesbian population. Public Opinion Quarterly, 72(4), 753-767. https://doi.org/ 10.1093/poq/nfn049

Mazzuca, J. (2004). Gay rights: US more conservative than Britain and Canada. https://news.gallup.com/poll/13561/gay-rightsus-more-conservative-than-britain-canada.aspx

Messner, M. (2004). Becoming 100 percent straight. In J. Coakley \& P. Donnelly (Eds.), Inside sports. Routledge.

Miller, D. T., \& Prentice, D. A. (1996). The construction of social norms and standards. In E. T. Higgins \& A. W. Kruglanski (Eds.), Social psychology: Handbook of basic principles (pp. 799-829). The Guilford Press.

Mishel, E. (2016). Discrimination against queer women in the US workforce: A résumé audit study. Socius, 2, 1-13. https://doi. org/10.1177/2378023115621316

Mize, T., \& Manago, B. (2018). Precarious sexuality: How men and women are differentially categorized for similar sexual behavior. American Sociological Review, 83(2), 305-330. https://doi. org/10.1177/0003122418759544

Monteith, M., Deneen, N., \& Tooman, G. (1996). The effect of social norm activation on the expression of opinions concerning gay men and Blacks. Basic and Applied Social Psychology, 18(3), 267-288. https://doi.org/10.1207/s15324834basp1803_2

Moore, D., \& Norris, F. (2005). Empirical investigation of the conflict and flexibility models of bisexuality. Journal Of Bisexuality, 5(1), 5-25. https://doi.org/10.1300/J159v05n01_02

Office for National Statistics - Annual Population Survey. (2019). Sexual Orientation, UK: 2017. https://www.ons.gov.uk/ peoplepopulationandcommunity/culturalidentity/sexuality/ bulletins/sexualidentityuk/2017
Paolini, S., Hewstone, M., Cairns, E., \& Voci, A. (2004). Effects of direct and indirect cross-group friendships on judgments of Catholics and Protestants in Northern Ireland: The mediating role of an anxiety-reduction mechanism. Personality and Social Psychology Bulletin, 30(6), 770-786. https://doi.org/10.1177/ 0146167203262848

Peery, D., \& Bodenhausen, G. (2008). Black + White = Black: Hypodescent in reflexive categorization of racially ambiguous faces. Psychological Science, 19(10), 973-977. https://doi.org/ 10.1111/j.1467-9280.2008.02185.x

Pettigrew, T., Wagner, U., \& Christ, O. (2010). Population ratios and prejudice: Modelling both contact and threat effects. Journal of Ethnic and Migration Studies, 36(4), 635-650. https://doi.org/ 10.1080/13691830903516034

Pinsof, D., \& Haselton, M. (2017). The effect of the promiscuity stereotype on opposition to gay rights. PLoS One, 12(7), e0178534. https://doi.org/10.1371/journal.pone.0178534

Plant, E., \& Devine, P. (2003). The antecedents and implications of interracial anxiety. Personality and Social Psychology Bulletin, 29 (6), 790-801. https://doi.org/10.1177/0146167203029006011

Powell, B., Quadlin, N. Y., \& Pizmony-Levy, O. (2015). Public opinion, the courts, and same-sex marriage: Four lessons learned. Social Currents, 2(1), 3-12. https://doi.org/10.1177/ 2329496514562964

Pratto, F., Cidam, A., Stewart, A.L., Zeineddine, F. B., Aranda, M., Aiello, A., Chryssochoou, X., Cichocka, A., Cohrs, J. C., Durrheim, K., \& Eicher, V. (2013). Social Dominance in context and in individuals: Contextual moderation of robust effects of social dominance orientation in 15 languages and 20 countries. Social Psychological and Personality Science, 4(5), 587-599. https://doi.org/10.1177/1948550612473663

Pratto, F., Sidanius, J., Stallworth, L., \& Malle, B. (1994). Social dominance orientation: A personality variable predicting social and political attitudes. Journal of Personality and Social Psychology, 67(4), 741-763. https://doi.org/10.1037/00223514.67.4.741

Savin-Williams, R. (2016). Sexual orientation: Categories or continuum? Commentary on Bailey et al. (2016). Psychological Science in the Public Interest, 17(2), 37-44. https://doi.org/doi. org/10.1177/1529100616637618

Schwartz, K., Joseph, P., \& Simmons, L. (2001). Contact quality and attitudes toward the elderly. Educational Gerontology, 27(2), 127-137. https://doi.org/10.1080/03601270151075525

Tankard, M., \& Paluck, E. (2016). Norm perception as a vehicle for social change. Social Issues and Policy Review, 10(1), 181-211. https://doi.org/10.1111/sipr.12022

Vandello, J., Bosson, J., Cohen, D., Burnaford, R., \& Weaver, J. (2008). Precarious manhood. Journal of Personality and Social Psychology, 95(6), 1325-1339. https://doi.org/10.1037/a0012453

Van Dick, R., Wagner, U., Pettigrew, T. F., Christ, O., Wolf, C., Petzel, T., Castro, V. S., \& Jackson, J. S. (2004). Role of perceived importance in intergroup contact. Journal of Personality and Social Psychology, 87(2), 211-227. https://doi.org/10.1037/ 0022-3514.87.2.211

Wagner, U., Christ, O., Pettigrew, T. F., Stellmacher, J., \& Wolf, C. (2006). Prejudice and minority proportion: Contact instead of threat effects. Social Psychology Quarterly, 69(4), 380-390. https://doi.org/10.1177/019027250606900406

Wagner, U., Van Dick, R., Pettigrew, T., \& Christ, O. (2003). Ethnic prejudice in East and West Germany: The explanatory power of intergroup contact. Group Processes \& Intergroup Relations, 6(1), 22-36. https://doi.org/10.1177/1368430203006001010

West, K., \& Cowell, N. (2015). Predictors of prejudice against lesbians and gay men in Jamaica. The Journal of Sex Research, 52(3), 296-305. https://doi.org/10.1080/00224499.2013.853725 
Whitley, B. E. Jr. (1999). Right-wing authoritarianism, social dominance orientation, and prejudice. Journal of Personality and Social Psychology, 77, 126-134. https://doi.org/10.1037/ 0022-3514.77.1.126

Whitley, B. E. Jr. \& Kite, M. E. (1995). Sex differences in attitudes toward homosexuality: A comment on Oliver and Hyde (1993). Psychological Bulletin, 117(1), 146-158. https://doi.org/ 10.1037/0033-2909.117.1.146

Zarate, M., \& Smith, E. (1990). Person categorization and stereotyping. Social Cognition, 8(2), 161-185. https://doi.org/ 10.1521/soco.1990.8.2.161

Zakrisson, I. (2005). Construction of a short version of the Right-Wing Authoritarianism (RWA) scale. Personality and Individual Differences, 39(39), 863-872. https://doi.org/10.1016/j.paid.2005.02.026

\section{History}

Received June 25, 2020

Revision received December 18, 2020

Accepted December 18, 2020

Published online May 31, 2021

\section{Authorship}

Keon West conceived the idea. Keon West, Martha Lucia BorrasGuevara, Thomas Morton, and Katy Greenland developed the theory, designed and worked on the implementation of the research, the analysis of the results, and the writing of the manuscript.

\section{Funding}

This work has been supported by the European Research Council (fund no. Starting grant 2017 to Keon West).

\section{ORCID}

Martha Lucia Borras-Guevara

(iD https://orcid.org/0000-0001-9280-226X

\section{Martha Lucia Borras-Guevara}

Equalab

Department of Psychology

Goldsmiths, University of London

Whitehead Building

New Cross

London, SE14 6NW

United Kingdom

m.guevara@gold.ac.uk 


\section{Appendix}

\section{Full List of Fragile Heterosexuality Items Shown to Participants (Study 3)}

\section{Fragile Heterosexuality (in Men)}

1. If a "straight" man has sex with a man, he must be gay.

2. It only takes one gay experience for a man to no longer be straight.

3. Heterosexuality is not a permanent state, men can slip into homosexuality.

4. Under certain conditions any heterosexual man can be tempted by homosexuality.

5. For some "straight" men, the only thing between them and being gay is a few drinks.

6. Even if a "straight" man has fooled around with someone of the same sex in the past, that still doesn't make him gay. (R)

7. A "straight" man might have fantasised about someone of the same sex in the past, but that doesn't make him gay. (R)

8. If a "straight" man has thought about what it would be like to have sex with a man, that still doesn't mean that he is gay. (R)

9. Being attracted to another man at some point doesn't change the fact that a man is straight. (R)

10. Even if he has had his share of same-sex encounters in the past, it doesn't change the fact that a man is straight $(\mathrm{R})$.

11. Just because a man has had some sexual experience with men in the past, that doesn't mean that he's gay (R). You can't describe yourself as a straight man if you have fooled around with someone of the same sex.

12. If you have had a same sex encounter, no matter how long ago it might have been, then you can't describe yourself as a straight man.

13. If a man has had more sexual experiences with women than with men, then he is probably ok to describe himself as straight. (R)

14. If a man has had more sexual experiences with women than with men, then he is probably ok to describe himself as straight.

\section{Fragile Heterosexuality (in Women)}

1. If a "straight" woman has sex with a woman, she must be a lesbian.
2. It only takes one lesbian experience for a woman to no longer be straight.

3. Heterosexuality is not a permanent state, women can slip into homosexuality.

4. Under certain conditions any heterosexual woman can be tempted by homosexuality.

5. For some "straight" women, the only thing between them and being lesbian is a few drinks.

6. Even if a "straight" woman has fooled around with someone of the same sex in the past, that still doesn't make her a lesbian. (R)

7. A "straight" woman might have fantasised about someone of the same sex in the past, but that doesn't make her a lesbian. (R)

8. If a "straight" woman has thought about what it would be like to have sex with a woman, that still doesn't mean that she is a lesbian. (R)

9. Being attracted to another woman at some point doesn't change the fact that a woman is straight (R)

10. Even if she has had her share of same-sex encounters in the past, it doesn't change the fact that a woman is straight. (R)

11. Just because a woman has had some sexual experience with women in the past, that doesn't mean that she's a lesbian. (R)

12. You can't describe yourself as a straight woman if you have fooled around with someone of the same sex.

13. If you have had a same sex encounter, no matter how long ago it might have been, then you can't describe yourself as a straight woman.

14. If a woman has had more sexual experiences with men than with women, then she is probably ok to describe herself as straight.

\section{Fragile Homosexuality (in Men)}

1. If a "gay" man has sex with a woman, he must be straight.

2. It only takes one straight experience for a man to no longer be gay.

3. Homosexuality is not a permanent state, men can slip into heterosexuality.

4. Under certain conditions any homosexual man can be tempted by heterosexuality.

5. For some "gay" men, the only thing between them and being straight is a few drinks.

6. Even if a "gay" man has fooled around with someone of the opposite sex in the past, that still doesn't make him straight (R)

7. A "gay" man might have fantasised about someone of the opposite sex in the past, but that doesn't make him straight $(\mathrm{R})$ 
8. If a "gay" man has thought about what it would be like to have sex with a woman, that still doesn't mean that he is straight $(\mathrm{R})$

9. Being attracted to a woman at some point doesn't change the fact that a man is gay (R)

10. Even if he has had his share of opposite-sex encounters in the past, it doesn't change the fact that a man is gay $(\mathrm{R})$

11. Just because a man has had some sexual experience with women in the past, that doesn't mean that he's straight $(\mathrm{R})$

12. You can't describe yourself as a gay man if you have fooled around with someone of the opposite sex

13. If you have had an opposite sex encounter, no matter how long ago it might have been, then you can't describe yourself as a gay man.

14. If a man has had more sexual experiences with men than with women, then he is probably ok to describe himself as gay.

\section{Fragile Homosexuality (in Women)}

1. If a "lesbian" has sex with a man, she must be straight.

2. It only takes one straight experience for a woman to no longer be a lesbian.

3. Homosexuality is not a permanent state, women can slip into heterosexuality.

4. Under certain conditions any homosexual woman can be tempted by heterosexuality

5. For some "lesbians", the only thing between them and being straight is a few drinks.

6. Even if a "lesbian" has fooled around with someone of the opposite sex in the past, that still doesn't make her straight $(\mathrm{R})$

7. A "lesbian" might have fantasised about someone of the opposite sex in the past, but that doesn't make her straight. (R)

8. If a "lesbian" has thought about what it would be like to have sex with a man, that still doesn't mean that she is straight. (R)

9. Being attracted to a man at some point doesn't change the fact that a woman is a lesbian.

10. Even if she has had her share of opposite-sex encounters in the past, it doesn't change the fact that a woman is a lesbian. (R)

11. Just because a woman has had some sexual experience with men in the past, that doesn't mean that she's a lesbian. (R)

12. You can't describe yourself as a lesbian if you have fooled around with someone of the opposite sex.

13. If you have had an opposite sex encounter, no matter how long ago it might have been, then you can't describe yourself as a lesbian.
14. If a woman has had more sexual experiences with women than with men, then she is probably ok to describe herself as a lesbian.

\section{Full list of Fragile Heterosexuality Items Shown to Participants \\ (Study 4)}

1. If a "straight" person has sex with someone of the same sex, they must really be gay.

2. It only takes one gay experience for a person to no longer be straight.

3. Heterosexuality is not a permanent state, people can slip into homosexuality.

4. Under certain conditions any heterosexual person can be tempted by homosexuality.

5. For some "straight" people, the only thing between them and being gay is a few drinks.

6. Even if a "straight" person has fooled around with someone of the same sex in the past, that still doesn't make them homosexual.

7. A "straight" person might have fantasised about someone of the same sex in the past, but that doesn't make them homosexual.

8. If a "straight" person has thought about what it would be like to have sex with someone of the same sex, that still doesn't mean that $s /$ he is gay.

9. Being attracted to someone of the same sex at some point doesn't change the fact that a person is straight.

10. Even if someone has had his/her share of same-sex encounters in the past, it doesn't change the fact that a person is straight.

11. Just because someone has had some same-sex sexual experience in the past, that doesn't mean that $\mathrm{s} / \mathrm{he}$ is gay.

12. You can't describe yourself as straight if you have fooled around with someone of the same sex.

13. If you have had a same sex encounter, no matter how long ago it might have been, then you can't describe yourself as straight.

14. If a person has had more opposite-sex sexual experiences than same-sex sexual experiences, then it is probably OK to describe them as straight.

\section{Distractor Items Within the Fragile Heterosexuality Items}

1. Public nudity is perverse; nudists often have unhealthy sexual intentions.

2. Nakedness should be kept private; only a small number of special people should ever see you naked.

3. If given the chance, you would probably go naked on a nude beach. 
4. Public nudity (e.g., on a nude beach or at a festival) can be enjoyable and healthy.

5. Everyone should try some kind of nudist or naturist experience at least once.

6. There is nothing wrong with public nudity.

7. People who take part in public nudity do not respect their bodies enough.

\section{Estimates of Gay/Lesbian Population}

1. What percentage of the overall population would you estimate is actually gay or lesbian?

2. What percentage of the overall population would you estimate is openly either gay or lesbian?

\section{Social Dominant Orientation}

1. It is OK if some groups have more of a chance in life than others.

2. Inferior groups should stay in their place.

3. To get ahead in life, it is sometimes okay to step on other groups.

4. We should have increased social equality.

5. It would be good if groups could be equal.

6. We should do what we can to equalize conditions for different groups.

7. In setting priorities, we must consider all groups.

8. We should not push for group equality.

9. Group equality should be our ideal.

10. Superior groups should dominate inferior groups.

\section{Right-Wing Authoritarianism}

1. There are many radical, immoral people trying to ruin things; the society ought to stop them.

2. Our forefathers ought to be honored more for the way they have built our society, at the same time we ought to put an end to those forces destroying it.

3. Our country needs free thinkers, who will have the courage to stand up against traditional ways, even if this upsets many people.

4. God's laws about abortion, pornography, and marriage must be strictly followed before it is too late, violations must be punished.

5. Many good people challenge the state, criticize the church and ignore "the normal way of living".

6. Our society would be better off if we showed tolerance and understanding for untraditional values and opinions.
7. The society needs to show openness towards people thinking differently, rather than a strong leader, the world is not particularly evil or dangerous.

8. The "old-fashioned ways" and "old- fashioned values" still show the best way to live.

9. Our country needs a powerful leader, in order to destroy the radical and immoral currents prevailing in society today.

10. It is better to accept bad literature than to censor it.

11. The situation in the society of today would be improved if troublemakers were treated with reason and humanity.

12. If the society so wants, it is the duty of every true citizen to help eliminate the evil that poisons our country from within.

13. People ought to put less attention to the Bible and religion, instead, they ought to develop their own moral standards.

14. Facts show that we have to be harder against crime and sexual immorality, in order to uphold law and order.

15. It would be best if newspapers were censored so that people would not be able to get hold of destructive and disgusting material.

\section{Prejudice Against Gay People}

1. I think homosexuals are disgusting.

2. Homosexuality is a perversion.

3. Homosexuality is a natural expression of sexuality.

4. Sex between two people of the same sex is just plain wrong.

5. Homosexuality is merely a different kind of lifestyle that should NOT be condemned.

\section{Contact Quantity}

For the following areas, please indicate how frequently do you personally have contact with people who are gay/lesbian, on a scale from 1 to 7, $1=$ being never and $7=$ very often .

1. University/Workplace.

2. Neighborhood.

3. Among friends.

4. Among acquaintances.

\section{Contact Quality}

This question concerns the contact (i.e., interactions) that you have had with people who are gay and/or lesbian.

1. How would you rate the contact you have had with gays/lesbians (from 1 to 6,1 = being very unpleasant to $6=$ very pleasant $)$. 